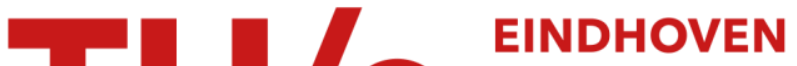 UNIVERSITY OF TECHNOLOGY
}

\section{Grain-size dependence of sliding wear in tetragonal zirconia polycrystals}

\section{Citation for published version (APA):}

He, Y. J., Winnubst, L., Burggraaf, A. J., Verweij, H., Varst, van der, P. G. T., \& With, de, G. (1996). Grain-size dependence of sliding wear in tetragonal zirconia polycrystals. Journal of the American Ceramic Society, 79(12), 3090-3096. https://doi.org/10.1111/j.1151-2916.1996.tb08081.x

DOI:

10.1111/j.1151-2916.1996.tb08081.x

Document status and date:

Published: 01/01/1996

\section{Document Version:}

Publisher's PDF, also known as Version of Record (includes final page, issue and volume numbers)

\section{Please check the document version of this publication:}

- A submitted manuscript is the version of the article upon submission and before peer-review. There can be important differences between the submitted version and the official published version of record. People interested in the research are advised to contact the author for the final version of the publication, or visit the $\mathrm{DOI}$ to the publisher's website.

- The final author version and the galley proof are versions of the publication after peer review.

- The final published version features the final layout of the paper including the volume, issue and page numbers.

Link to publication

\section{General rights}

Copyright and moral rights for the publications made accessible in the public portal are retained by the authors and/or other copyright owners and it is a condition of accessing publications that users recognise and abide by the legal requirements associated with these rights.

- Users may download and print one copy of any publication from the public portal for the purpose of private study or research.

- You may not further distribute the material or use it for any profit-making activity or commercial gain

- You may freely distribute the URL identifying the publication in the public portal.

If the publication is distributed under the terms of Article 25fa of the Dutch Copyright Act, indicated by the "Taverne" license above, please follow below link for the End User Agreement:

www.tue.nl/taverne

Take down policy

If you believe that this document breaches copyright please contact us at:

openaccess@tue.nl

providing details and we will investigate your claim. 


\title{
Grain-Size Dependence of Sliding Wear in Tetragonal Zirconia Polycrystals
}

\author{
Yingjie He, Louis Winnubst, ${ }^{*}$ Anthonie J. Burggraaf, and Henk Verweij ${ }^{*}$ \\ Faculty of Chemical Technology, Laboratory for Inorganic Materials Science, University of Twente, \\ 7500 AE Enschede, The Netherlands
}

\author{
Paul G. Th. van der Varst and Bert de With ${ }^{*}$
}

Faculty of Chemical Technology, Laboratory of Solid State Chemistry and Materials Science, Eindhoven University of Technology, $5600 \mathrm{MB}$ Eindhoven, The Netherlands

Using a pin-on-plate tribometer with the reciprocating motion of $\mathrm{SiC}$ against yttria-doped tetragonal zirconia polycrystal (Y-TZP) plates, the friction and wear of Y-TZP ceramics were investigated as a function of grain size in dry $\mathrm{N}_{2}$ at room temperature. The results showed that the overall wear resistance increased as the grain size of Y-TZP ceramics decreased. For grain sizes $\leq 0.7 \mu \mathrm{m}$, the wear results revealed a Hall-Petch type of relationship $\left(d^{-1 / 2}\right)$ between wear resistance and grain size. In this case, the main wear mechanisms were plastic deformation and microcracking. For grain sizes $\geq 0.9 \mu \mathrm{m}$, the wear resistance was proportional to the reciprocal of the grain diameter. In this regime, delamination and accompanying grain pullout were the main mechanisms. In this case, the phase transformation to monoclinic zirconia had a negative effect on the wear resistance of TZP ceramics. The coefficient of friction tended to be higher for fine-grained TZP-SiC couples than for coarse-grained TZP-SiC couples, whereas, for a specific regime of grain size, the coefficient of friction was almost independent of the grain size.

\section{Introduction}

$\mathrm{T}$ HE wear resistance of ceramics is affected by microstructural parameters, such as grain size, porosity, and grainboundary behavior. ${ }^{1}$ The results obtained by Marshall et al. ${ }^{2}$ show that the high-purity and coarse-grained alumina ceramics reveal a low grinding resistance. As a first-order approximation, a relation between wear resistance and the reciprocal square root of grain size has been found in abrasive-wear tests with oxide ceramics. ${ }^{3,4}$ Recently, Cho et al.${ }^{5}$ used fracture mechanics to demonstrate the existence of a Hall-Petch-type relation between wear-damage stress and grain size of polycrystalline alumina ceramics. Furthermore, Liu and Fine ${ }^{6}$ extended the fracture-mechanics analysis in the Cho work to quantify the dependence of sliding wear on grain size for polycrystalline alumina, in the case of grain-boundary microfracture.

At present, considerable attention is given to properties and possible applications of nanocrystalline ceramics. ${ }^{7,8}$ Ultrafinegrained yttria-doped tetragonal zirconia polycrystal (Y-TZP) ceramics show improved high-temperature mechanical properties $^{9}$ and low-temperature aging resistance in water, especially

R. O. Scattergood-contributing editor

Manuscript No. 192821. Received March 6, 1996; approved June 10, 1996

Supported by the Innovative Research Program on Technical Ceramics (IOP-TK)

with the financial aid of the Dutch Ministry of Economic Affairs.

"Member, American Ceramic Society.

*Author to whom all correspondence should be addressed. at $150^{\circ}-250^{\circ} \mathrm{C} .{ }^{10}$ Recent studies ${ }^{10,11}$ indicate that a high toughness (8-9 $\mathrm{MPa} \cdot \mathrm{m}^{1 / 2}$ ) can be obtained in these ceramics without the occurrence of an irreversible martensitic transformation. High wear resistance of nanocrystalline materials may be expected, especially if little or no porosity is present. ${ }^{4,12}$ To optimize TZP ceramics for high-wear-resistant application, identification of the friction and wear behavior of TZP ceramics, as a function of grain size, is necessary. For zirconia ceramics, the amount of transformed TZP, as influenced by the grain size, can affect mechanical properties, wear resistance, and wear mechanisms. Therefore, the present investigation also is concerned with the influence of the phase transformation of TZP on the wear rate. The wear tests on Y-TZP ceramics have been conducted on materials made with two types of powders: a nanocrystalline powder prepared by a chloride precipitation method and a commercially available powder (TZ-3Y, Tosoh, Tokyo, Japan).

\section{Experimental Procedures}

\section{(1) Wear Tests}

Wear experiments were performed with a pin-on-plate tribometer, as shown in Fig. 1. A polished silicon carbide (SiC) sphere (pin) with a diameter of $4 \mathrm{~mm}$ mounted in a copper tube slides reciprocally against a stationary Y-TZP plate. Tests were conducted at room temperature in a dry $\mathrm{N}_{2}$ atmosphere (humidity $<1 \%$ ) under a normal load of $8 \mathrm{~N}$, corresponding to the initial Hertzian contact pressure of $858 \mathrm{MPa}$. The track length was $10 \mathrm{~mm}$ with a frequency of $4 \mathrm{~Hz}$ (for the pin), corresponding to a maximum sliding velocity of $12.5 \times 10^{-2} \mathrm{~m} / \mathrm{s}$ or an average velocity of $8 \times 10^{-2} \mathrm{~m} / \mathrm{s}$. The testing time was $\sim 20 \mathrm{~h}$, corresponding to a sliding distance of $5.8 \mathrm{~km}$. The friction force

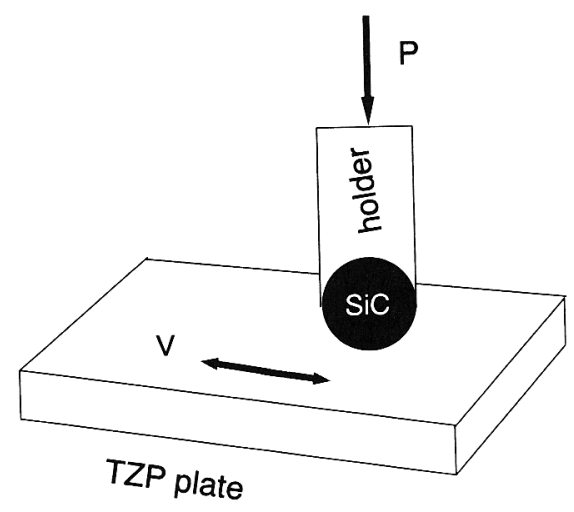

Fig. 1. Schematic diagram of pin-on-plate wear rig. Pin moves reciprocally on a static plate. 
Table I. Friction and Wear Properties for Sliding Wear of a SiC Ball on a TZP Plate

\begin{tabular}{|c|c|c|c|c|c|c|}
\hline \multirow[b]{2}{*}{ Sample } & \multirow{2}{*}{$\begin{array}{l}\text { Grain size } \\
\qquad(\mu \mathrm{m})\end{array}$} & \multirow[b]{2}{*}{ Friction coefficient, $f_{c}$} & \multirow{2}{*}{$\begin{array}{c}\text { Roughness, } R_{a}(\mathrm{TZP})^{*} \\
(\mathrm{~nm})\end{array}$} & \multirow{2}{*}{$\begin{array}{c}\text { Wear rate, } K(\mathrm{TZP}) \\
\left(\times 10^{-6} \mathrm{~mm}^{3} \cdot(\mathrm{N} \cdot \mathrm{m})^{-1}\right)\end{array}$} & \multicolumn{2}{|c|}{ Fraction monoclinic } \\
\hline & & & & & Polished & Worn surface \\
\hline & & & ZY5.7 material & & & \\
\hline G1 ZY5.7 & 0.18 & $0.42 \pm 0.08$ & 1482 & $1.08 \pm 0.22$ & 0 & 0 \\
\hline G2 ZY5.7 & 0.36 & $0.38 \pm 0.07$ & 1787 & $1.82 \pm 0.16$ & 0 & 0 \\
\hline G3 ZY5.7 & 0.50 & $0.36 \pm 0.05$ & 2214 & $2.38 \pm 0.40$ & 0 & 0 \\
\hline G4 ZY5.7 & 0.70 & $0.38 \pm 0.06$ & 2743 & $2.63 \pm 0.28$ & $<3$ & $5-8$ \\
\hline G5 ZY5.7 & 0.90 & $0.30 \pm 0.06$ & 4602 & $4.74 \pm 0.45$ & $<3$ & $50-60$ \\
\hline G6 ZY5.7 & 1.20 & $0.33 \pm 0.04$ & 5866 & $6.67 \pm 0.08$ & 20 & $50-60$ \\
\hline G7 ZY5.7 & 1.50 & $0.31 \pm 0.05$ & 7428 & $8.00 \pm 0.70$ & 50 & $50-60$ \\
\hline A1-TZ-3Y & 0.34 & $0.50 \pm 0.08$ & $\begin{array}{c}\text { TZ-3Y material } \\
2068\end{array}$ & $1.60 \pm 0.30$ & 0 & 0 \\
\hline A2-TZ-3Y & 0.90 & $0.38 \pm 0.08$ & 6493 & $5.95 \pm 0.60$ & $<3$ & $40-45$ \\
\hline
\end{tabular}

*Center line average roughness ${ }^{33}$ measured along the direction perpendicular to sliding. ${ }^{\dagger}$ This specimen was prepared by sinter forging at $40 \mathrm{MPa}$.

was determined by a force transducer. Friction forces were simultaneously sampled under external triggering control with a computerized data-acquisition system and were continuously measured during the tests. ${ }^{13}$

After wear testing, the specimens were cleaned with ethanol in an ultrasonic bath and then dried at $120^{\circ} \mathrm{C}$ for $4 \mathrm{~h}$ in a drying stove and subsequently cooled while blowing with dry $\mathrm{N}_{2}$. The specific wear rate, $K_{w}\left(=K_{\mathrm{pin}}\right.$ for the $\mathrm{SiC}$ pin and $K_{\text {plate }}$ for the $\mathrm{Y}$-TZP plate), was obtained as

$$
K_{w}=\frac{W_{m}}{\rho L P}
$$

where $W_{m}$ is the mass loss, $\rho$ the density, $L$ the total wear path length, and $P$ the normal load.

\section{(2) Sample Preparation and Characterization}

Commercially available $\mathrm{SiC}$ spheres with mirror-polished surfaces (GIMEX Technische Keramiek B.V., Geldermalsen, The Netherlands) were used in all cases as pin materials. The plates were $\mathrm{ZrO}_{2}$ with $5.7 \mathrm{~mol} \% \mathrm{YO}_{1.5}$ (ZY5.7), prepared by gel-precipitation synthesis, and TZ-3Y (with the same composition as ZY5.7) (Tosoh Europe B.V., Amsterdam, The Netherlands). The gel-precipitation (or "chloride") method is based on precipitation of a $0.2 \mathrm{MHCl}$ solution of $\mathrm{ZrCl}_{4}$ and $\mathrm{YCl}_{3}$ with ammonia. ${ }^{14}$ The average crystallite size was $8 \mathrm{~nm}$ for the chloride powder and $34 \mathrm{~nm}$ for the TZ-3Y powder. More powder properties are given in Ref. 14. All powders were uniaxially pressed at $50 \mathrm{MPa}$ in a rectangular die and then isostatically pressed at $400 \mathrm{MPa}$ and sintered for 2-5 $\mathrm{h}$ at temperatures of $1150^{\circ}-1570^{\circ} \mathrm{C}$ in a tube furnace. The average grain size was measured using the linear-intercept technique ${ }^{15}$ on scanning electron microscopy (SEM) pictures. The bulk density of $>98 \%$ was determined for all sintered samples using the Archimedes technique in mercury. For the specimens of $0.18 \mu \mathrm{m}$ grain size with $98 \%$ density, sinter forging was used as described by $\mathrm{He}$ et al. ${ }^{16}$ and Boutz et al. ${ }^{17}$ The specimens for wear tests were finally polished, using $0.05 \mu \mathrm{m} \mathrm{Al} \mathrm{O}_{3}$ powder, to a final roughness of $<80 \mathrm{~nm}$. Finally, all specimens were annealed at $950^{\circ} \mathrm{C}$ for $10 \mathrm{~min}$ (heating and cooling rate of $\left.2^{\circ} \mathrm{C} / \mathrm{min}\right)$. The Vickers hardness $\left(H_{\mathrm{v}}\right)$ was determined with a Vickers indentor (Isser Stedt Garant $250 \mathrm{RD}$ ) at a load of $98 \mathrm{~N}$. The hardness values were almost the same $(12.8 \pm 0.4 \mathrm{GPa})$ for the specimens with different grain sizes used in this study.

The surface roughness of the plates and profiles of some wear tracks on the plate were measured with a profilometer (Model Dek-Tak 3030, Sloan, Santa Barabara, CA). Worn tracks were analyzed by SEM (Model JSM-35CF, JEOL, Tokyo, Japan). The phase composition of TZP ceramics before and after sliding wear were measured by X-ray diffractometry (XRD) with $\mathrm{Cu} K \alpha$ radiation (Model PW 1710, Philips Scientific Instruments, Almelo, The Netherlands). The volume fraction of monoclinic zirconia was determined by XRD using the equation of Toraya et al. ${ }^{18}$ Adhesive particles on the worn surface and wear debris were analyzed using energy-dispersive $\mathrm{X}$-ray analysis (EDAX).

\section{Results}

\section{(1) Tribological Properties of TZP Plates}

To investigate the influence of grain size on wear behavior of TZP ceramics systematically, all samples have almost the same

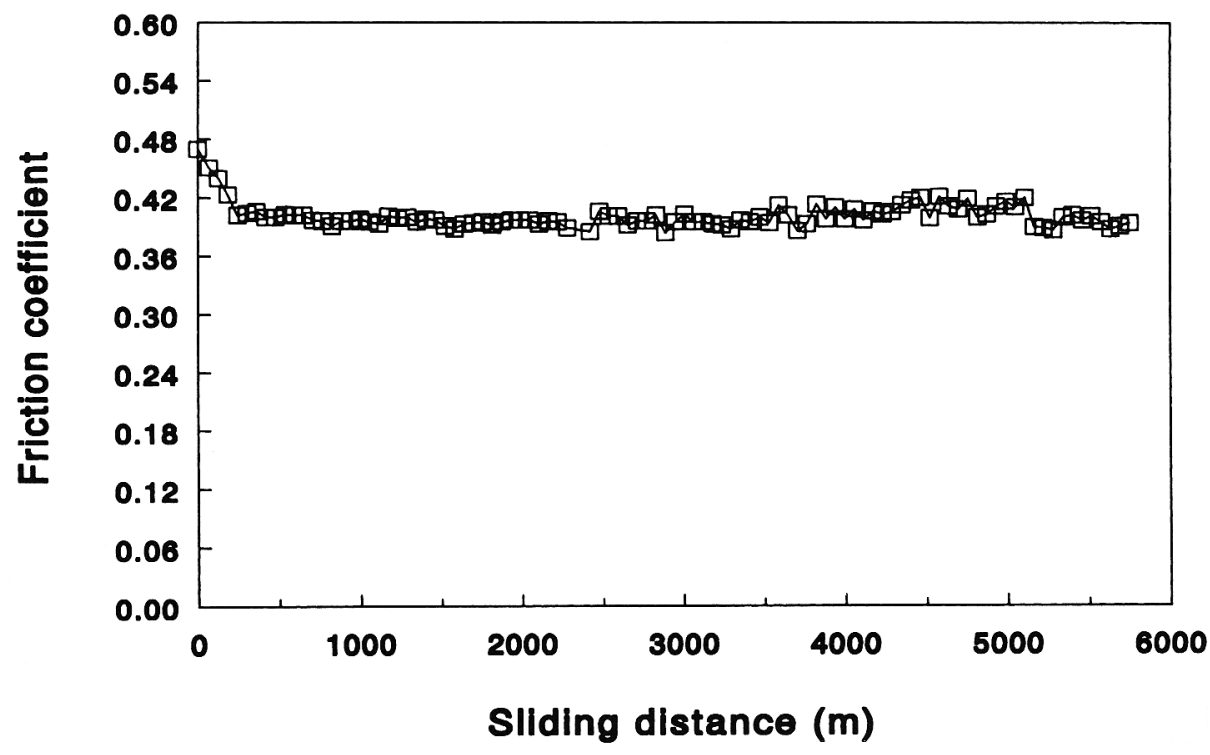

Fig. 2. Coefficient of friction of specimen $\mathrm{G} 1-\mathrm{SiC}$ couple as a function of sliding distance, under a normal load of $8 \mathrm{~N}$ and at an average velocity of $0.08 \mathrm{~m} / \mathrm{s}$. 


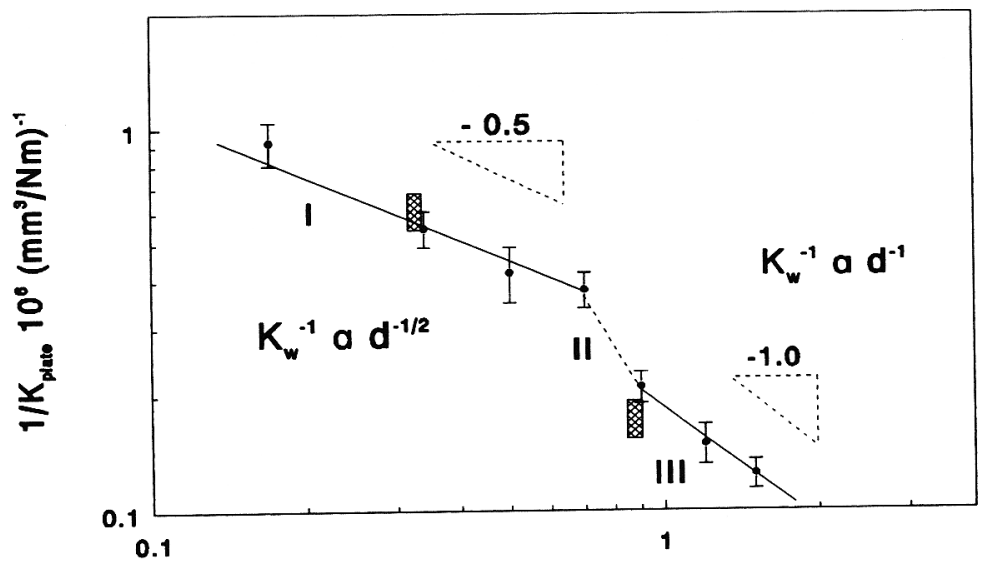

Grain size (um)

Fig. 3. Wear resistance as a function of average grain size for TZP ceramics with an $\mathrm{SiC}$ pin sliding at an average velocity of $0.08 \mathrm{~m} / \mathrm{s}$ and a normal load of $8 \mathrm{~N}$. Results with an error bar on the plotted curve are for ZY5.7 materials. Crosshatched area gives results for TZ-3Y materials.

density, to eliminate the influence of porosity on wear resistance. In the present study, the relative densities of all samples are $98 \%-98.5 \%$. The friction and wear properties are summarized in Table I. The friction coefficient, $f_{c}$, is an average of at least three measurements obtained after the running-in stage. The friction coefficients as a function of time (distance) indicate that, for all tests, a running-in time of $<3.3 \mathrm{~h}$ (about $950 \mathrm{~m}$ ) exists, after which a stationary value is reached. Figure 2 gives an example of the experimental results. For ZY5.7 ceramics, stationary $f_{c}$ values of $0.36-0.42$ are obtained and are independent of grain size in the grain-size region $\leq 0.7 \mu \mathrm{m}$. A relatively
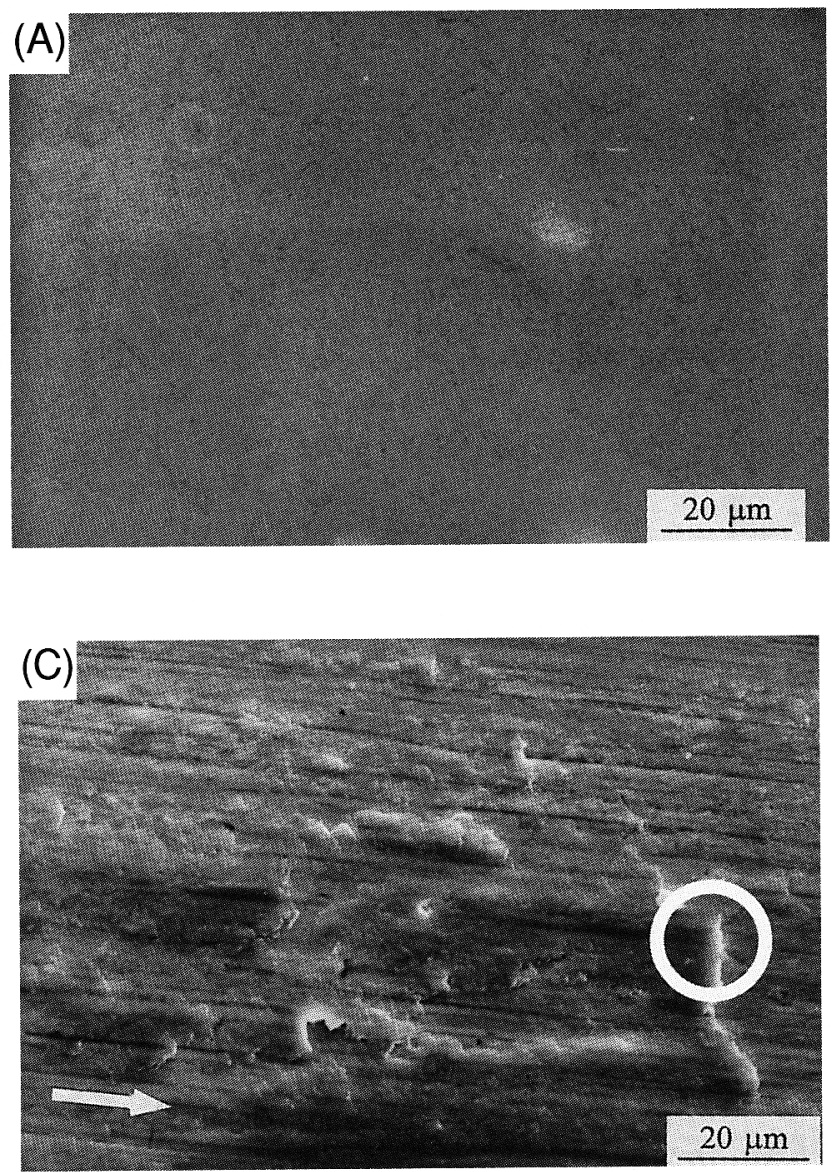

low $f_{c}$ value $(\sim 0.3)$ is observed for the coarse-grained ceramics $(>0.9 \mu \mathrm{m})$. The same trend is observed for TZ-3Y ceramics, in which $f_{c}$ values of 0.50 and 0.38 are found for the materials with grain sizes of 0.34 and $0.90 \mu \mathrm{m}$, respectively.

As shown in Fig. 3, the wear resistance $\left(K_{\text {plate }}{ }^{-1}\right.$, which is the recipocal of the wear rate, $K_{\text {plate }}$ ) as a function of grain size can be divided in two parts. One part (region I in Fig. 3) is the grainsize region $<0.7 \mu \mathrm{m}$, whereas the other part (region III in Fig. 3 ) is in the grain-size region $>0.9 \mu \mathrm{m}$; region II in Fig. 3 must be regarded as a transition range. Using the power relation $K_{\text {plate }}{ }^{-1} \propto d^{-n}$ ( $d$ is the average grain size), as indicated by Zum
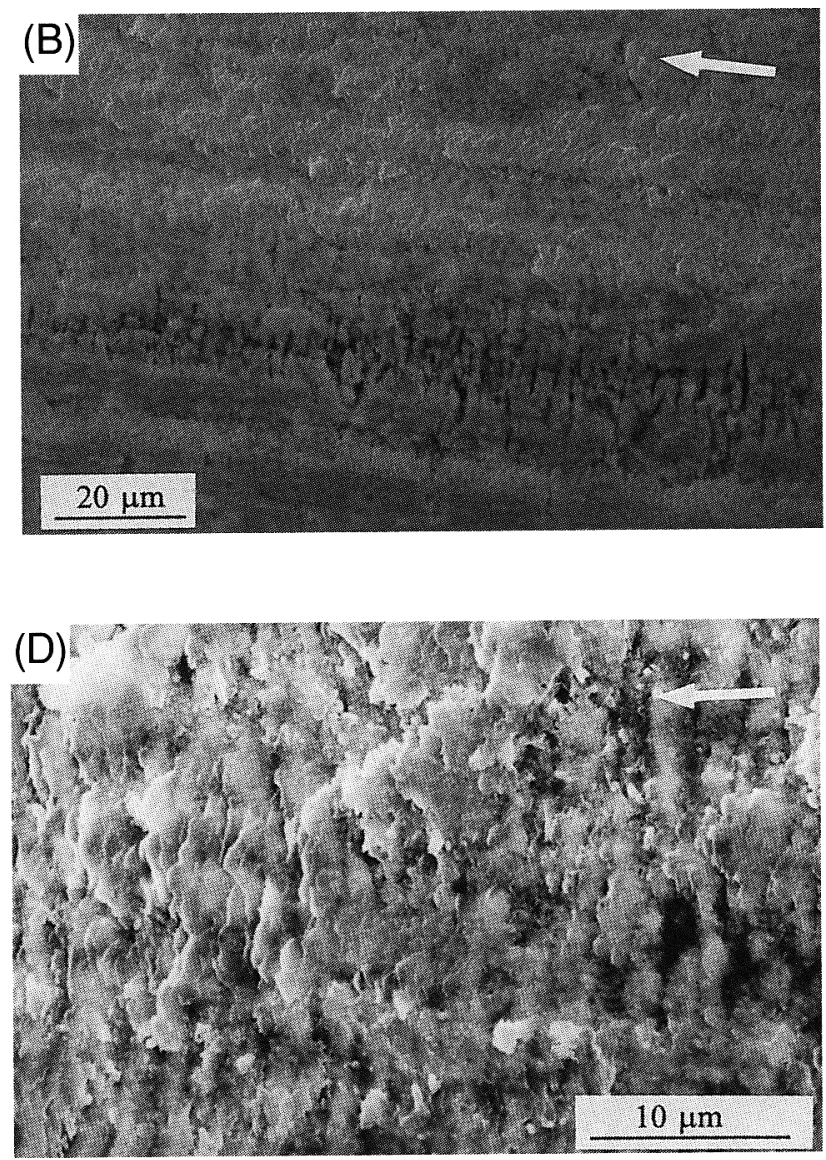

Fig. 4. Morphologies of specimen G1 with a grain size of $0.18 \mu \mathrm{m}$. ((A) polished surface, (B and C) worn surface, and (D) magnified version of Fig. 4(B)). Arrow indicates one direction of the reciprocal sliding. 
Gahr et al., ${ }^{19}$ values of $n=0.5$ for region I and $n=1.0$ for region III are obtained. These results reveal a Hall-Petch-type dependence for region I. Interestingly, the change of $n$ values from 0.5 to 1.0 correlates to the onset of the phase transformation to monoclinic zirconia. From Table I, the martensitic phase transformation of TZP ceramics can be induced by fracture or sliding-wear processes in region III but not in region I. For specimen G5, 50\%-60\% of TZP is transformed to the monoclinic phase, which is a larger percentage than that induced by single-edge notched beam (SENB) fracture. Evidence has been given that cycling stresses enhance the phase transformation. ${ }^{20}$

\section{(2) Morphology of Worn Surfaces of TZP Plates}

Typical SEM micrographs of the worn surface of ZY5.7 ceramics after sliding $5.8 \mathrm{~km}$ are presented in Figs. 4-7. The micrographs of the polished surfaces before sliding are similar for all specimens. As an illustration, a micrograph of a polished sample is shown in Fig. 4(A). Figures 4(B)-(D) show the wear tracks of ZY5.7 ceramics with a grain size of $0.18 \mu \mathrm{m}$. The morphologies observed indicate that plastic deformation, microcracks, microcutting or microploughing, and adhesion of wear debris occur during dry sliding. In this case, plastic deformation and microcracking are the major wear mechanisms. The plastic deformation of the materials is attributed to the large shear stresses acting on the loaded zone. Some of the plastic deformation may result from adhesion and smearing of small wear debris particles. ${ }^{21}$ Fatigue processes due to repeated abrading on the top surface and the corresponding plastic deformation of the surface may result in microcracking. Microcracking patterns are found perpendicular to the sliding direction, as shown in Fig. 4(B). These microcracks are more often present at the turning point of the wear track than in the middle. In Fig. 4(C), typical plastic deformation patterns, one of which is marked with the white circle, are shown. Figure 4(D) indicates
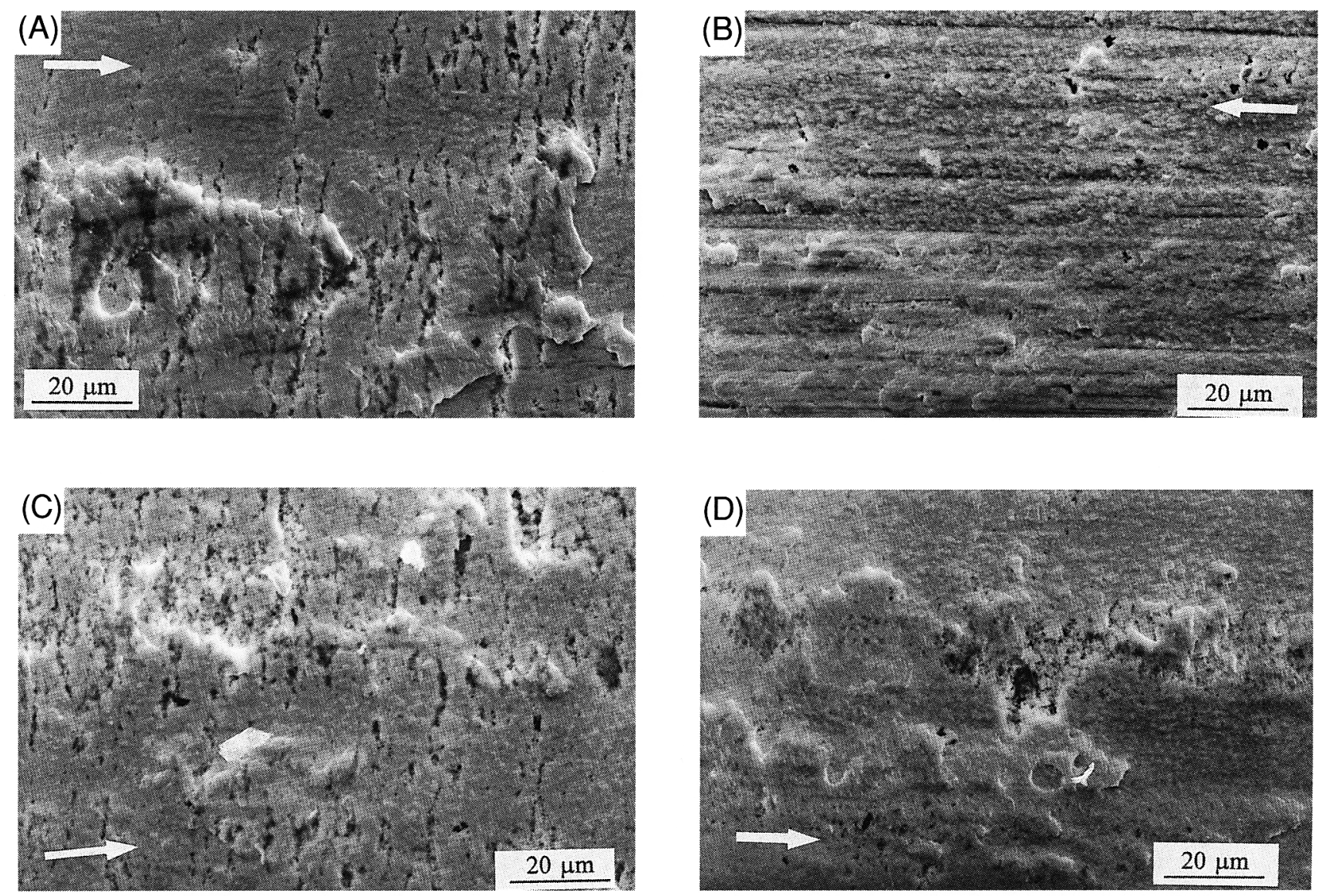

some plastic deformation, accompanied by cracklike patterns. Wear debris adheres easily to the microcracked parts. Similar wear mechanisms occur in specimens G3 and G4 but with a larger contribution of microcracking and less plastic deformation (Fig. 5). Overall observations of the morphologies of specimens G1-G4 indicate that a change in the grain size of the TZP plate in this regime does not result in a drastic change in wear morphology or in wear mechanism.

However, the specimens with grain sizes of $0.9-1.5 \mu \mathrm{m}$, specimens G5 and G7, give a difference in wear morphology (Figs. 6 and 7), if compared to the finer-grained ceramics. The wear tracks show a pronounced surface roughness. Figures 6(A) and (B) show a detachment of the deformed surface layer for specimen G5, and Fig. 7(A) shows a similar detachment for specimen G7. A large and deep layer has been removed from the plastically deformed surfaces by a delamination process, as shown in Figs. 6(C) and 7(B). Figure 7(C) is a high-magnification view of a portion of the wear pattern that is generated on the subsurface after delamination. Fracture at the subsurface is observed to be mainly of the intergranular type, with very limited transgranular fracture. Pits due to grain or particle pullout are found.

A more detailed examination of the wear tracks reveals an absence of microcracks at the contact surface in Figs. 6 and 7. This reflects the influence of the phase transformation from tetragonal to monoclinic resulting in a volume increase. For specimens G1-G4, where no transformation occurs, significant evidence of microcracking at the contact surface can easily be found. The delamination wear for region III is caused by nucleation and propagation of microcracks at a subsurface level. Specimens G5 and G7 show the same fracture behavior; only the degree of wear increases as the grain size increases. The morphology of specimens G5 and G7 also shows more wear particles adhering to the contact surface, forming elevated, smooth regions (see Fig. 6(D)). For TZ-3Y ceramics, inspection

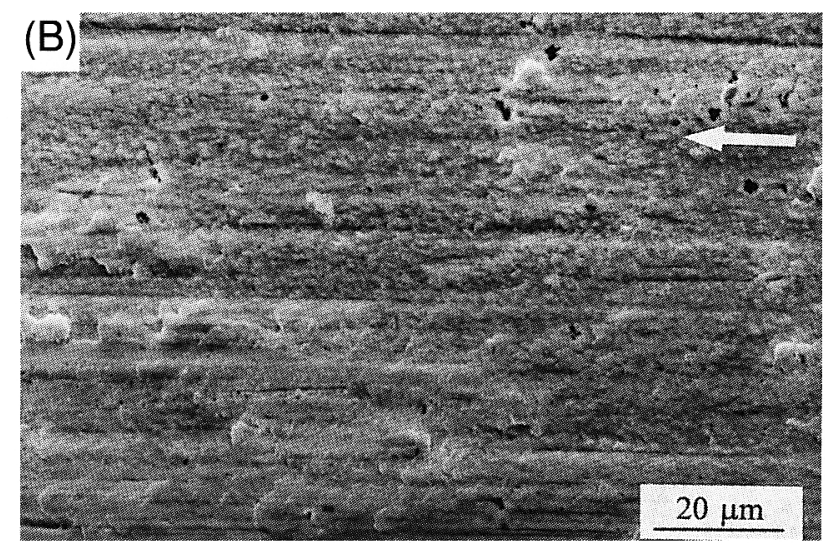

Fig. 5. Morphologies of specimens (A and B) G3 and (C and D) G4 with grain sizes of 0.50 and $0.70 \mu m$, respectively; (A) and (C) are taken from the turning point area; (B) and (D) are from the middle of the wear track. Arrow indicates one direction of the reciprocal sliding. 
of wear-track morphologies indicates that specimen Al behaves similar to the fine-grained ZY5.7 materials, whereas specimen A2 reveals wear tracks similar to those of coarse-grained specimens G5 and G7.

The roughness $\left(R_{a}\right)$ values, perpendicular to the sliding direction, of worn TZP surfaces after $5.8 \mathrm{~km}$ of sliding tests are given in Table I. The average $R_{a}$ value strongly depends on and increases with grain size. The $R_{a}$ data are related to particle removal at the contact surfaces. According to Van den Berg and de With, ${ }^{22}$ the $R_{a}$ values give an indication of the geometry of both contacting surfaces. In turn, a larger $R_{a}$ value results in a decrease in the number of contact points and, hence, at certain loads, causes an increase in local contact pressure. The increased contact pressure leads to an increased shear stress, which may, in turn, affect the wear process.

\section{Discussion}

\section{(1) Wear Resistance and Hall-Petch-Type Relation at Grain Sizes $\leq 0.7 \mu \mathrm{m}$}

The experimental results shown an unambiguous relation between grain size of Y-TZP ceramic and wear resistance under unlubricated sliding conditions. In region I with grain size $\leq 0.7 \mu \mathrm{m}$, the dependence of the wear resistance $\left(K_{\text {plate }}{ }^{-1}\right)$ of TZP ceramics on grain size can be described as $K_{\text {plate }}{ }^{-1} \propto d^{-1 / 2}$ (Fig. 3). This result is similar to that of Rice and co-workers, ${ }^{3,4}$ who found a Hall-Petch-type relation between the wear resistance and the average grain size, $d$, in $\mathrm{MgO}$ and $\mathrm{Al}_{2} \mathrm{O}_{3}$ ceramics during abrasive wear. This also was reported by Zum Gahr et al. ${ }^{19}$ for TZP ceramics in unidirectional sliding, who suggested that this should be expected if plastic deformation or brittle fracture is considered as the dominant process. The HallPetch relation was first introduced by $\mathrm{Hall}^{23}$ and $\mathrm{Petch}^{24}$ in
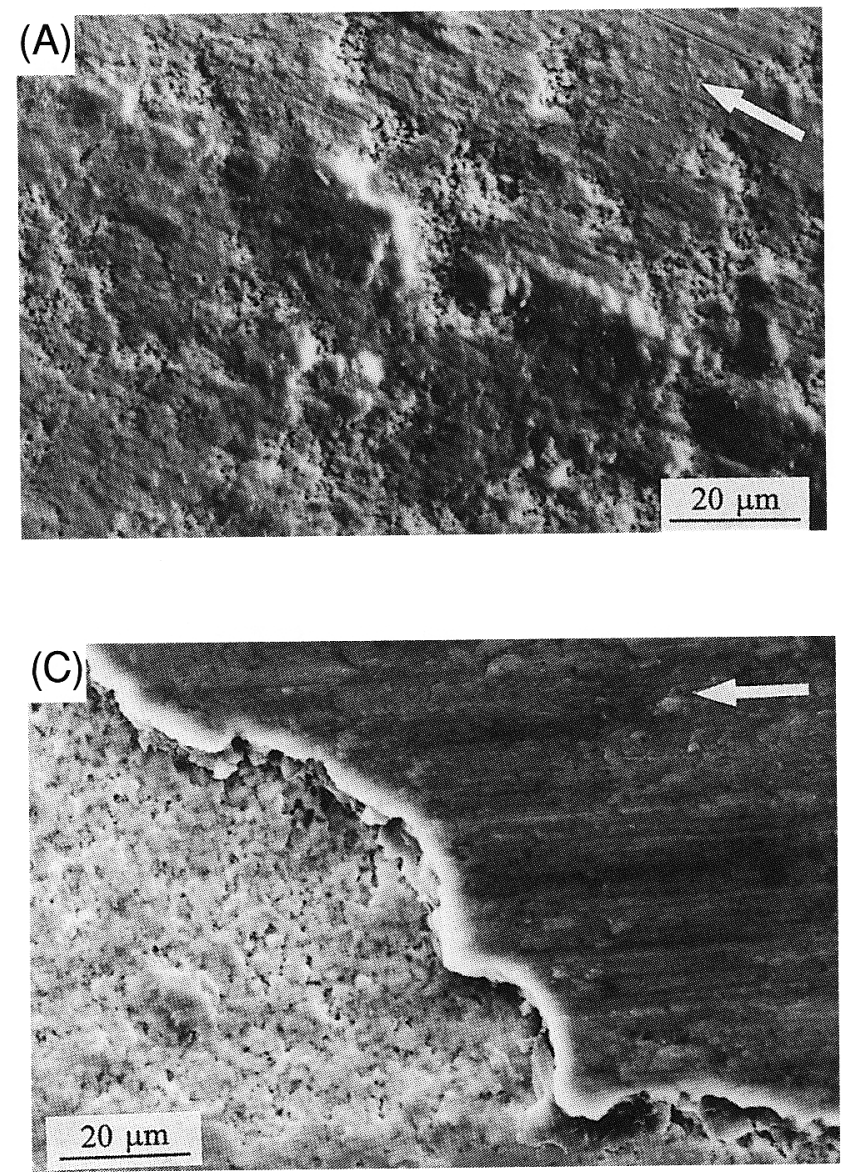

polycrystalline metals undergoing plastic deformation controlled by dislocation pileup. The yield stress, $\sigma_{y}$, was proportional to the inverse square root of $d$. Fracture is predicted to occur as a result of the nucleation of microcracks by the interaction of slip planes or dislocation pileups at grain boundaries. Evidence for plastic deformation in ceramic materials also has been given by other investigators. ${ }^{21,25,26}$

In the present study, plastic deformation and accompanying microcracking of TZP are clearly observed from detailed SEM micrographs of the worn surfaces (see Figs. 4 and 5). Here, the surface-removal process is controlled by microfracture, which is caused, in turn, by plastic deformation and/or flaws. Fracture mechanics cited by Cho et al..$^{5}$ are adopted to provide a theoretical understanding of this process. They supposed that extended microcracking can be generated in ceramics from grain-boundary flaws. These flaws are either present or generated by stress concentration at deforming elements. Using the models of Cho et al. ${ }^{5}$ and Liu et al., ${ }^{6}$ local microfracture may occur when the damage-induced stress, $\sigma_{D}$, exceeds the strength of the material. This stress, $\sigma_{D}$, is the sum of three stresses: the accumulated stress, $\sigma_{A}$, during the sliding process; the tensile stress, $\sigma_{T}$, due to the applied stress field; and the internal stresses, ${ }^{6} \sigma_{l}$, resulting from the thermal expansion anisotropy of the grains.

$$
\sigma_{D}=\sigma_{A}+\sigma_{T}+\sigma_{I}
$$

The critical condition for local microfracture is that the sum of the stress-intensity factors must be larger than or equal to the intrinsic grain-boundary toughness. Assuming that the size of the initial flaws is proportional to $d$ and that grain-boundary microcracks are initiated from these flaws, the critical $\sigma_{D}$ can be expressed as

$$
\sigma_{D}=\sigma_{I}\left(\frac{d_{c}^{S}}{d}\right)^{1 / 2}
$$

where $d_{c}^{S}$ is the critical grain size corresponding to microfracture, under the action of the internal stress alone, caused by
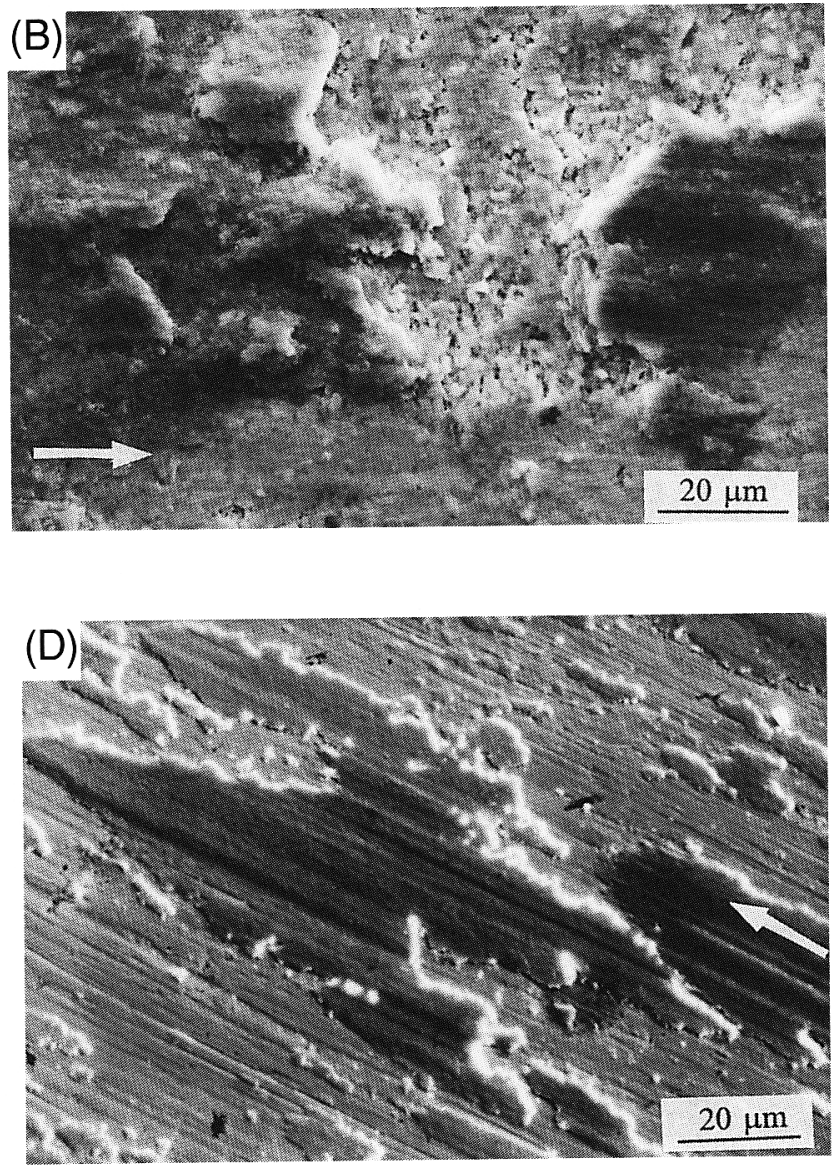

Fig. 6. Morphologies of specimen G5 with a grain size of $0.90 \mu \mathrm{m}$. Arrow indicates one direction of the reciprocal sliding. 

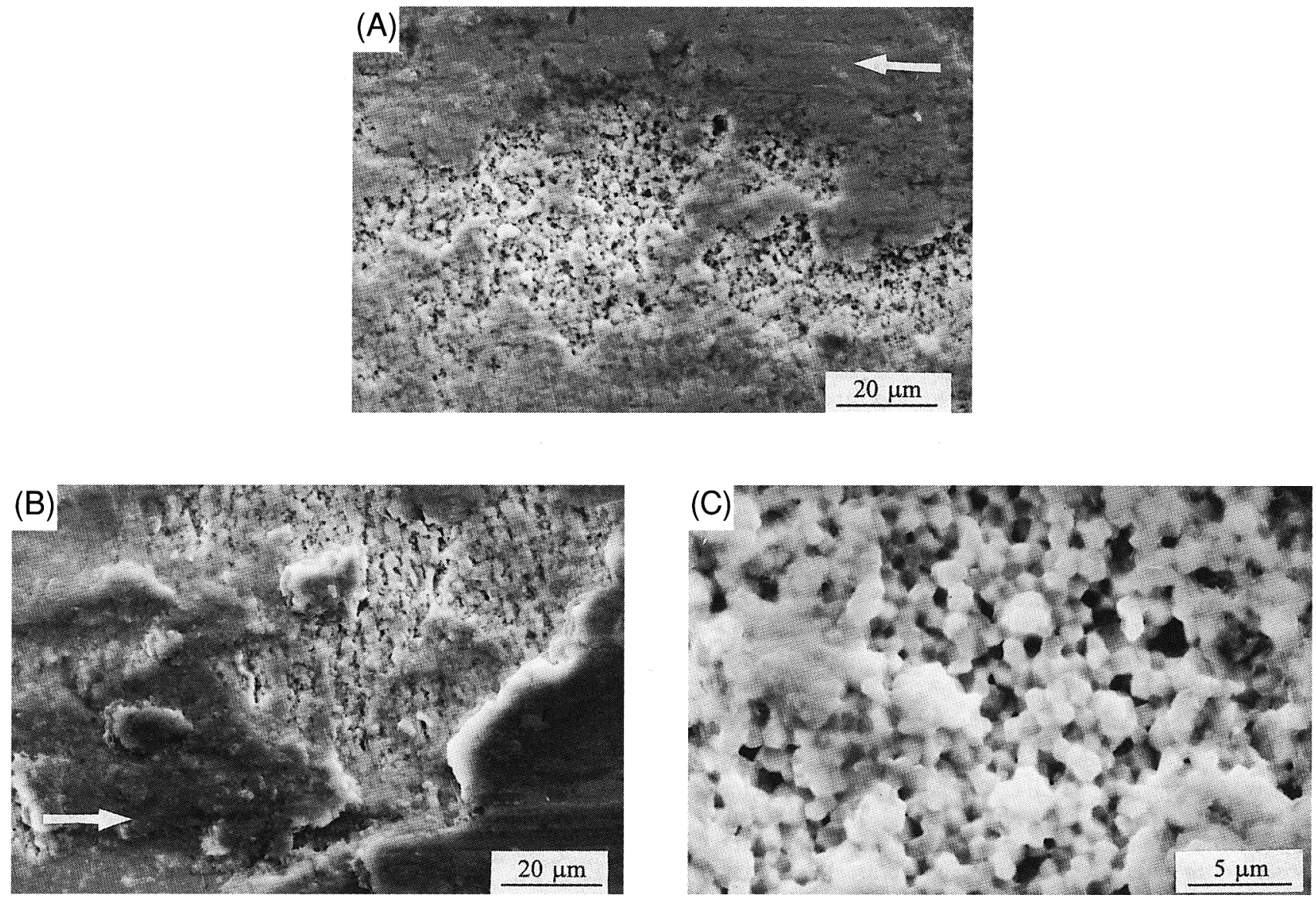

Fig. 7. Morphologies of specimen G7 with a grain size of $1.50 \mu \mathrm{m}((\mathrm{A})$ general worn surface, (B) wear scar after delamination, and (C) magnified version of Fig. 7(A) at the subsurface area after delamination). Arrow indicates one direction of the reciprocal sliding.

thermal anisotropy $\left(\sigma_{T}=0\right.$ and $\left.\sigma_{A}=0\right)$. In this case, the critical $\sigma_{D}$ acting in the ceramics depends on the grain size as a type of Hall-Petch relation $\left(d^{-1 / 2}\right)$. A similar relation also was suggested by Winnubst et al. ${ }^{27}$ in brittle ceramics. They found that the fracture energy is correlated with grain size (proportional to $d^{-1 / 2}$ ). Using energy-conservation arguments and the Cho et al. model, ${ }^{5}$ Wang et al. ${ }^{28}$ developed an empirical model to express the volumetric wear loss in terms of extrinsic and intrinsic properties of ceramics. Wear particles are thought to be produced when the accumulation of energy during the sliding process exceeds the energy of new surface formation. The critical energy density, with dimensions of stress (see Wang et al. ${ }^{28}$ ) has been proposed as being proportional to $\sigma_{D}$. Thus, the wear volume, $V$, can be expressed as

$$
V=C\left(\frac{\sigma_{\max }}{\sigma_{D}}\right) \frac{L P}{H_{v}}
$$

where $C$ is a constant, $L$ the sliding distance, $P$ the normal load, and $\sigma_{\max }$ the maximum external tangential stress (related to the friction coefficient $f_{c}$ and the normal load $P$ ). For comparison with the results presented in this study, Eq. (4) is rewritten in terms of $K_{\text {plate }}{ }^{-1}$ :

$$
K_{\text {plate }}^{-1}=\left(\frac{V}{L P}\right)^{-1}=C^{\prime} \frac{\sigma_{D} H_{\mathrm{v}}}{\sigma_{\max }}
$$

where $C^{\prime}$ is a constant. Inserting Eq. (2) into Eq. (5), the wear resistance $K_{\text {plate }}^{-1}$ is obtained as

$$
K_{\text {plate }}^{-1}=C^{\prime} \frac{H_{\mathrm{v}}}{\sigma_{\max }} \sigma_{I}\left(\frac{d}{d_{c}^{S}}\right)^{-1 / 2}
$$

This expression clearly reveals a Hall-Petch-type relation between wear resistance and grain size. For the present study on Y-TZP with average grain sizes $\leq 0.7 \mu \mathrm{m}$, the critical grain size, $d_{c}^{S}$, and the internal stress, $\sigma_{I}$, are assumed to be constant. ${ }^{6}$ The variables $f_{c}$ and $H_{\mathrm{v}}$ are independent of the grain size in the present range and, hence, also are constant. Therefore, in this region, the experimental results agree with the theoretical model qualitatively described in this paper. The actual wear mechanisms observed in grain-size region (I)-plastic deformation and microcracking are the dominant mechanismsindicate that Eq. (6) can indeed be used for Y-TZP ceramics.

\section{(2) Wear Resistance and Phase Transformation at Grain Sizes $\geq 0.9 \mu \mathrm{m}$}

For Y-TZP with grain sizes $\geq 0.9 \mu \mathrm{m}$ (region III of Fig. 3), the results show a wear resistance inversely proportional to the grain size (power of -1 ). A change is observed, as a function of grain size, from mild wear (region I) by plastic deformation and microcracks to severe wear (region III) by delamination. Also, a phase transformation is observed from the tetragonal to the monoclinic phase in grain sizes $\geq 0.9 \mu \mathrm{m}$. The transformation of TZP particles is induced by the stress during reciprocating sliding. As a result of this transformation, a compressive layer is formed at the worn surface. Hence, the formation and propagation of microcracks on the contact surface are prevented, and earlier formed microcracks can be healed. In this way, the transformation process results in a positive influence on wear resistance. On the other hand, a tensile stress can develop beneath the compressive layer, forming internal stresses in local areas. These internal stresses promote microcrack nucleation at, for instance, pores and grain boundaries. Fatigue lateral microcracks also can be produced at weak interfaces. The removal of particles starts when these subsurface cracks intersect at the contact surface of the body. Altogether, the removal of the material is identical to that described in the delamination theory of wear. ${ }^{29}$ As grain sizes increase, the 
internal stresses increase, because of more zirconia phase transformation, subsequently leading to a large degree of delamination. The high wear rate in partially stabilized zirconia (PSZ) or $\mathrm{TZP}$, due to the delamination, also has been reported elsewhere in reciprocating-sliding processe ${ }^{30}$ or grinding by diamonds. ${ }^{31}$

For such delamination-wear processes, the damage-induced stress, $\sigma_{D}$, expressed in Eqs. (2) and (3) can be used for the present case as well. The only difference with the situation in fine-grained materials is that an internal stress introduced by the phase transformation also must be included. In combination with a microcracking theory of $\mathrm{Fu}$ and Evans, ${ }^{32}$ another empirical expression for the wear rate can be developed. This wear model is based on material removal by grain pullout, which is similar to the wear mechanisms in the present study. Using the wear model of Liu et al., ${ }^{6}$ the wear rate, as a function of grain size, $d$, is expressed as

$$
K_{\text {plate }}=\frac{1}{\nu P} \frac{\mathrm{d} V(t)}{\mathrm{d} t}=\frac{c \dot{\sigma}_{D}}{d_{c}^{S} \sigma_{I} \nu P} d
$$

where $V(t)$ is the wear volume, $t$ the sliding time, $v$ the average sliding velocity, $c$ a coefficient with the dimensions of volume loss, and $\dot{\sigma}_{D}$ the damage-stress accumulation rate $\left(\mathrm{d} \sigma_{D} / \mathrm{d} t\right.$, which is independent of grain size $\left.{ }^{5}\right) ; d_{c}^{S}$ and $\sigma_{I}$ are the same as in Eq. (3). Equation (7) shows that the wear resistance is inversely proportional to the grain diameter.

\section{Conclusions}

The wear resistance in TZP ceramics is increased by a factor of 8 when the grain size decreases from 1.5 to $0.18 \mu \mathrm{m}$. A Hall-Petch-type relation between wear resistance and grain size is observed for grain sizes $\leq 0.7 \mu \mathrm{m}$. In this case, the main wear mechanisms are plastic deformation and microcracking.

For relatively coarse-grained materials, with grain sizes $\geq 0.9 \mu \mathrm{m}$, the wear resistance of the material is proportional to the reciprocal of the grain diameter, where delamination and accompanying grain pullout are predominant during sliding wear. In this case, partial zirconia phase transformation can be induced by shear stresses during sliding.

The occurrence of a zirconia phase transformation prevents the formation of microcracks on the top surface. On the other hand, this transformation weakens the grain boundaries at the subsurface layer by using internal stresses that promote delamination and grain pullout, resulting in more wear particles in the coarse-grained TZP materials.

For grain sizes $\leq 0.7 \mu \mathrm{m}$, the value of the friction coefficient is independent of the grain size. For the coarse-grained material $(\geq 0.9 \mu \mathrm{m})$, the friction coefficient is slightly less than that of the fine-grained material. Large amounts of $\mathrm{SiC}$ wear debris generated during sliding are responsible for this lower friction coefficient.

Acknowledgments: The authors are indebted to P. M. V. Bakker for powder preparation, J. Snoeyenbos for machining samples, and J. Boeijsma for XRD measurements.

\section{References}

${ }^{1}$ O. O. Ajayi and K. C. Ludema, "Surface Damage of Structural Ceramics: Implication for Wear Modelling," Wear, 124, 237-57 (1988).

${ }^{2}$ D. B. Marshall, B. R. Lawn, and R. F. Cook, "Microstructural Effects on Grinding of Alumina and Glass-Ceramics," J. Am. Ceram. Soc., 70 [6] C-139 C-140 (1987).

${ }^{3}$ R. W. Rice, "Micromechanics of Microstructural Aspects of Ceramic Wear," Ceram. Eng. Sci. Proc., 6 [7-8] 940-45 (1985).
${ }^{4}$ C. C. Wu, R. W. Rice, D. Johnson, and B. A. Platt, "Grain Size Dependence of Wear in Ceramics," Ceram. Eng. Sci. Proc., 6 [7-8] 995-1011 (1985).

${ }^{5}$ S. J. Cho, B. J. Hockey, B. R. Lawn, and S. J. Bennison, "Grain-Size and $R$-Curve Effects in the Abrasive Wear of Alumina," J. Am. Ceram. Soc., 72 [7] 1249-52 (1989).

${ }^{6} \mathrm{H}$. Liu and M. E. Fine, "Modeling of Grain-Size-Dependent MicrofractureControlled Sliding Wear in Polycrystalline Alumina," J. Am. Ceram. Soc., 76 [9] 2393-96 (1993).

${ }^{7}$ A. J. Burggraaf, "Stuijts Memorial Lecture 1991: Some New Developments in Ceramic Science and Technology,"J. Eur. Ceram. Soc., 9 [4] 245-50 (1992).

${ }^{8}$ A. J. Burggraaf, A. J. A. Winnubst, and H. Verweij, "Dense and Porous Nanostructured Ceramics and Composites"; pp. 561-76 in Third Euro-Ceramics, Vol. 3, Engineering Ceramics (Proceedings of the Third European Ceramic Society Conference, Madrid, Spain, Sept. 12-17, 1993). Edited by P. Duran and J. F. Fernandez. Faenza Editrice Iberica, S.L., Castellón de la Plana, Spain, 1993.

${ }^{9}$ G. S. A. M. Theunissen, J. S. Bouma, A. J. A. Winnubst, and A. J. Burggraaf, "Mechanical Properties of Ultra-Fine Grained Zirconia Ceramics," J. Mater. Sci., 27 [14] 4429-38 (1992).

${ }^{10}$ M. M. R. Boutz, A. J. A. Winnubst, and A. J. Burggraaf, "The Effect of Ceria-Codoping on Chemical Stability and Fracture Toughness of Y-TZP," J. Mater. Sci., 30, 1854-62 (1995).

${ }^{11}$ Y. J. He, A. J. A. Winnubst, C. D. Sagel-Ransijn, A. J. Burggraaf, and H. Verweij, "Enhanced Mechanical Properties by Grain Boundary Strengthening in Ultra-Fine Grained TZP Ceramics," J. Eur. Ceram. Soc., 16 [6] 601-12 (1996).

${ }^{12}$ Y. J. He, A. J. A. Winnubst, A. J. Burggraaf, H. Verweij, P. van der Varst, and G. de With, "Influence of Porosity on Friction and Wear of Tetragonal Zirconia Polycrystal," J. Am. Ceram. Soc., in press.

${ }^{13}$ P. H. J. van den Berg, G. de With, L. Dortmans, E. Kokmeijer, and G.-Z. $\mathrm{Cao}$, "Wear and Friction of Y-TZP Spheres Reciprocating against Various Sialon Plates," J. Mater. Sci., 281, 3187-96 (1993).

${ }^{14} \mathrm{~W}$. Groot Zevert, A. J. A. Winnubst, G. S. A. M. Theunissen, and A. J. Burggraaf, "Powder Preparation and Compaction Behaviour of Fine-Grained Y-TZP," J. Mater. Sci., 25, 3449-55 (1990).

${ }^{15}$ M. I. Mendelson, "Average Grain Size in Polycrystalline Ceramics," J. Am. Ceram. Soc., 52 [8] 443-46 (1969).

${ }^{16}$ Y. J. He, A. J. A. Winnubst, H. Verweij, and A. J. Burggraaf, "Sinter Forging of Zirconia Toughened Alumina," J. Mater. Sci., 29 [24] 6505-12 (1994).

${ }^{17}$ M. M. R. Boutz, A. J. A. Winnubst, A. J. Burggraaf, M. Nauer, and C. Carry, "Low Temperature Sinter Forging of Nanostructured Y-TZP"; pp. 275-83 in Science and Technology of Zirconia V. Edited by S. P. S. Badwal, M. J. Bannister, and R. H. J. Hannink. Technomic, Lancaster, PA, 1993.

${ }^{18} \mathrm{H}$. Toraya, M. Yoshimura, and S. Sōmiya, "Calibration Curve for Quantitative Analysis of the Monoclinic-Tetragonal $\mathrm{ZrO}_{2}$ System by X-ray Diffraction," J. Am. Ceram. Soc., 67 [6] C-119-C-121 (1984).

${ }^{19} \mathrm{~K}$.-H. Zum Gahr, W. Bundschuh, and B. Zimmerlin, "Effect of Grain Size on Friction and Sliding Wear of Oxide Ceramics," Wear, 162-164, 269-79 (1993).

${ }^{20} \mathrm{G}$. Grathwohl and T. Liu, "Strengthening of Zirconia-Alumina during Cyclic Fatigue Testing," J. Am. Ceram. Soc., 72 [10] 1988-90 (1989).

${ }^{21}$ T. E. Fischer, M. P. Anderson, and S. Jahanmir, "Influence of Fracture Toughness on the Wear Resistance of Yttria-Doped Zirconium Oxide," J. Am. Ceram. Soc., 72 [2] 252-57 (1989).

${ }^{22}$ P. H. J. van den Berg and G. de With, "Wear and Strength of Mg-PSZ, Worn on Hardened Steel," J. Eur. Ceram. Soc., 8 [2] 123-33 (1991).

${ }^{23}$ E. O. Hall, "The Deformation and Ageing of Mild Steel: III Discussion of Results," Proc. Phys. Soc., London, B, 64, 747-53 (1951).

${ }^{24}$ N. J. Petch, "The Cleavage Strength of Polycrystals," J. Iron Steel Inst., 174, 25-28 (1953).

${ }^{25} \mathrm{~W}$. Bundschuh and K.-H. Zum Gahr, "Influence of Porosity on Friction and Sliding Wear of Tetragonal Zirconia Polycrystal," Wear, 151, 175-91 (1991).

${ }^{26}$ O. O. Ajayi and K. C. Ludema, "Formation of Transfer Film during Ceramics/Ceramics Repeat Pass Sliding"; pp. 349-59 in Wear of Materials. Edited by K. C. Ludema. American Society of Mechanical Engineers, New York, 1989.

${ }^{27}$ A. J. A. Winnubst, K. Keizer, and A. J. Burggraaf, "Mechanical Properties and Fracture Behaviour of $\mathrm{ZrO}_{2}-\mathrm{Y}_{2} \mathrm{O}_{3}$ Ceramics," J. Mater. Sci., 18 [7] 195866 (1983).

${ }^{28}$ Y. S. Wang, S. M. Hsu, and R. G. Munro, "A Wear Model for Alumina Sliding Wear"; pp. 1225-30 in Proceedings of the Japan International Tribology Conference, 1990, Vol. 2. Japan Society of Tribologists, Tokyo, Japan, 1990.

${ }^{29}$ N. P. Suh, "An Overview of the Delamination Theory of Wear," Wear, 44 [1] 1-16 (1977).

${ }^{30}$ G. W. Stachowiak and G. B. Stachowiak, "Unlubricated Friction and Wear Behaviour of Toughened Zirconia Ceramics," Wear, 132, 151-71 (1989).

${ }^{31}$ R. M. Hooper and J. E. Morgan, "Wear Processes in the Diamond Grinding of Zirconia Ceramics," Wear, 130, 353-56 (1989).

${ }^{32}$ Y. Fu and A. G. Evans, "Some Effects of Microcracks on the Mechanical Properties of Brittle Solids: I. Stress-Strain Relations," Acta Metall., 33 [8] 1515-23 (1985).

${ }^{33}$ S. Kalpakjian, Manufacturing Engineering and Technology; Chs. 2, 31, and 32. Addison-Wesley, New York, 1992. 